Research Article

\title{
Public Perception Analysis of Hot Topics in Intellectual Property Based on Microblog Data
}

\author{
Shi Dandan \\ School of Finance and Public Administration, Harbin University of Commerce, Harbin 150028, Heilongjiang, China \\ Correspondence should be addressed to Shi Dandan; 102064@hrbcu.edu.cn
}

Received 6 May 2021; Accepted 28 June 2021; Published 2 July 2021

Academic Editor: Zaoli Yang

Copyright ( 2021 Shi Dandan. This is an open access article distributed under the Creative Commons Attribution License, which permits unrestricted use, distribution, and reproduction in any medium, provided the original work is properly cited.

Public opinion is a crucial factor for government policy making, implementation, evaluation, and social development. This paper analyzes the public opinion perception of intellectual property subject based on microblog data and puts forward the concept and calculation model for the breadth, depth, and comprehensive value of public perception. Then, taking the opinion evaluation in microblog platform as an example, this paper studies the public perception of intellectual property subject and illustrates the changing trend of public perception through related events in microblog. The results show that the four topics of trademark, intellectual property, copyright, and patent are the hot topics of public perception, the breadth, depth, and comprehensive value of public perception for the four topics fluctuated greatly, on the whole. In addition, when the content of microblog is related to personal benefits, business benefits, and personal interests, it can cause widespread public concern. Additionally, the public mainly participate in the dissemination of public opinion on intellectual property subject through forwarding. Finally, this paper puts forward some suggestions from the perspective of how to maximize the effect of intellectual property policy.

\section{Introduction}

Online public opinion refers to the sum total of different attitudes, views, and opinions held by the public on some problems in real life expressed and disseminated through the Internet [1]. Public opinion perception plays an important role in government policy making, implementation, evaluation $[2,3]$, and social development, so it may not be able to maximize the effect of relevant policies without timely understanding of public feedback in the process of policy making and implementation. Therefore, exploring the law of public perception in the process of policy implementation can enhance the influential effect of policy and ultimately promote the degree of policy implementation [4]. At present, various countries and individuals are widely concerned with intellectual property rights. Improving the intellectual property policy can not only promote the national economic development and enhance the national competitive strength, but also help to stimulate individual enthusiasm for scientific research. Therefore, this paper takes China's intellectual property as the research object to explore the public's perception of China's intellectual property-related topics.

At present, with the rapid development of the Internet, the emergence of microblog, WeChat, Facebook, and Twitter provides a simple and fast tool for message dissemination. These network platforms cover a wide range of users, including grassroots, stars of various countries, enterprises, and government agencies, thus becoming an important information source for the government to understand the public's perception of policy topics [5]. Many scholars begin to pay attention to mining public opinion perception based on the information in the network platform. For example, Johan et al. extracted comments from Twitter to measure the impact of public mood on the stock market [6]. Andrei and Svetlana analyzed the function of Twitter in the communication of climate change and discussed the changes of related topics in tweets in different geographical locations and time states [7]. Lazard has revealed the main topics of discussion on FDA e-cigarette regulations on twitter through text mining software [8]. Besides, some scholars also analyzed the topics that the 
netizen cares about to judge the development direction of things by mining the user-generated content in online social platforms. Li et al. used the text mining technology to obtain the topic of perovskite solar cell technology then combined the patent data to identify the hot spots and development trends of perovskite solar cell technology [9]. Mohammadi et al. got the updates on topics in the health and biomedical research field based on Facebook platform [10]. Yang et al. identified the topic evolution trend in the online community using the user comment data in the Zhihu community [11]. Based on similar research paradigms, many other authors examined the public perception of other topics based on social network data, such as online consumer behavior [12], the evolution of $3 \mathrm{D}$ printing technology [13], motivation and satisfaction of tourists [14], and the effect of topics and sentiments on social media engagement [15].

The research on analyzing the intellectual property topic based on online network information is rare, and only a limited number of scholars have indirectly investigated the influential effect of intellectual property through survey data on network platforms. For example, Wang proposed the approach to the optimal resource configuration of intellectual property policy system using the Internet of Things (IoT) technology and big data [16]. Drita mainly analyzed the impact of intellectual property protection on the lives of its own people and concluded that the protection policy of intellectual property can promote the improvement of people's living standards [6]. Ariel proposed that there is a mutually beneficial relationship between intellectual property policy and antimonopoly law and confirmed that a sound intellectual property policy is conducive to the smooth implementation of antimonopoly law [17].

The above research has laid a foundation for the public perception analysis of policy related topics, but there are still some shortcomings: first, the existing work focuses on the impact of intellectual property policy on a country or on a certain aspect of national economy, ignoring the public perception of intellectual property after the implementation of intellectual property policy. Then, the existing studies do not accurately calculate the degree of public perception of a specific topic. In view of the limitations of existing research, this paper constructs a microblog based method to calculate the degree of public perception of intellectual property topics. In this method, the user's views of intellectual property topics in microblog platform are taken as the data source, and the public's perception of intellectual property topics is calculated from three perspectives of public perception breadth, depth, and comprehensive value.

The main contributions of this paper are as follows:

(1) The concepts of public perception breadth, depth, and comprehensive value based on microblog topic are defined

(2) The calculation methods of public perception breadth, depth, and comprehensive value are proposed

(3) The public perception of intellectual property topics is analyzed from four aspects: copyright, trademark, patent, and intellectual property
Other parts of this paper are as follows: Section 2 constructs the public perception calculation method; Section 3 , based on microblog data, carries out an empirical analysis of public perception of intellectual property topics; Section 4 summarizes the conclusion and puts forward some suggestions.

\section{Research Method}

2.1. Basic Definitions. Microblog has the characteristics of convenient and diverse participation channels, comprehensive content, wide user coverage, strong interactivity, rapid dissemination [18], convenient operation, and so on. These characteristics make microblog penetrate into all aspects of people's life in the form of "fragmented" information [19] and gradually become an important position for public opinion [20]. Therefore, based on the microblog platform, this paper analyzes the public perception of intellectual property topics from three aspects: the breadth, depth, and comprehensive value of public perception.

2.1.1. Breadth of Public Perception. There is no strict definition of the breadth of public perception. Generally, the scope and scale of a thing are regarded as an important index of its breadth calculation. For example, some scholars use government archives, rescue team logs, expert reports [21], and the number of relevant theme contents [22] published by users on social media platforms as the main way of public perception calculation. Therefore, this paper regards the scale of relevant content release of related network topics as the public perception breadth, that is, the breadth of public perception is measured according to the number of microblogs published on a topic in the microblog platform.

2.1.2. Depth of Public Perception. Similarly, there is no precise definition of the concept of public perception depth. The existing research mainly takes the word frequency of violence behavior, protest behavior of medical staff [23], and various public perception behaviors in the media [24] as calculation indexes in the time of event propagation. In this paper, the degree of public behavior on a certain network topic in the process of public opinion dissemination is regarded as the depth of public perception. For example, if a microblog user only clicks "like" on a topic or event, it means that the user does not have a strong idea of spreading this kind of content, but merely expresses the emotional tendency of approval, with limited perception; if a microblog user shares and reposts a topic, it means that the user has certain recognition of the reposted content and is very interested in such topics, and his perception degree is high. When a microblog user likes and comments on a topic, it indicates that the content of the topic has influenced the user and that the user has gained further cognition after thinking about the content of the microblog. Such actions reflect the strongest degree of perception. 
2.1.3. Comprehensive Value of Public Perception. Generally, almost no network topic can meet the needs and interests of all people at the same time, and it cannot be ruled out that some members of the public publish their opinions without careful study or understanding of an event or topic. Therefore, it is necessary to identify the core hot topic objects from a large amount of information. This paper comprehensively considers the behavior of like, forward, and comment and obtains the comprehensive value of public perception to determine the hot topic.

\subsection{Calculation Method}

(1) Public perception breadth index and calculation method: the most direct way to judge whether microblog users are concerned about an event is the number of posts in microblog [25]. In this paper, the number of microblogs after the publication of a certain topic is used as the calculation index of the public perception breadth.

(2) Index and calculation method of public perception depth: the transmission of public opinion is mainly through users' comments, like, and forward on a certain topic using social platform. These three behaviors are the most important ways for users to express their attitudes and views on topic content. At the same time, these three ways also show users' emotional tendency and their participation in public opinion. The lower the user's participation in public opinion, the lower the level of public perception depth.

For this reason, this paper refers to Ma's index [26] for quantifying user behavior and regards the number of likes $(\mathrm{CN})$ as a surface perception index, the number of forwards $(\mathrm{FN})$ as a shallow perception index, and the number of comments (LN) as a deep perception index.

(3) Comprehensive index of public perception and its calculation method: by means of weighted average aggregation operator, the comprehensive value of public perception is obtained by combining the number of likes, forwards, and comments. The calculation formula is

$$
C=W_{1} * \mathrm{CN}+W_{2} * \mathrm{FN}+W_{3} * \mathrm{LN}
$$

where $\mathrm{CN}$ is the number of comments, $\mathrm{FN}$ is the number of forwards, and LN is the number of likes. $W_{1}, W_{2}$, and $W_{3}$ are the weight of comment, forward, and like, respectively.

In order to guarantee the unity of subjectivity and objectivity of the index, this paper adopts the combination weighting method of subjective G1 method and objective entropy weight method to determine the weight, so as to enhance the scientificity and accuracy [27]. The weight formula of subjective and objective combination is as follows:

$$
W_{i}=\frac{\sqrt{\alpha_{i} \beta_{i}}}{\sum_{i=1}^{n} \sqrt{\alpha_{i} \beta_{i}}}, \quad(i=1,2,3, \cdots, n),
$$

where $\alpha_{i}$ is the subjective weight of the $i$ th index and $\beta_{i}$ is the objective weight of the $i$ th index.

\section{Empirical Results and Discussion}

3.1. Data Acquisition and Processing. In this paper, the microblog publishing time is limited to 2010-2018, and the seven topics in the field of intellectual property rights, including intellectual property, copyright, trademark, geographic labeling, integrated circuit distribution design, new plant varieties, and patent, are retrieved. We found that the keywords of intellectual property, copyright, and patent are statistically significant in quantity, while the topics of geographic labeling, integrated circuit distribution design, and new plant varieties are less numerous. At the same time, since the keyword "intellectual property" retrieved contains related contents of other six keywords, the perception analysis of intellectual property in this paper is divided into four topics, namely, trademark, intellectual property, copyright, and patent. The microblog data of the four topics are summarized monthly.

Microblog websites use the GET method to load data, that is, keyword parameters are directly attached to the API interface's web address to obtain data. The corresponding crawler also uses the same method, that is, after the API interface, it notifies the server to send the retrieved results of a keyword in a certain period of time through the specified parameters. In this process, it is necessary to configure the header file for the crawler in order to enable the crawler to "cheat" the server, so that the server mistakenly thinks that this is a real request from the browser. As the search function of microblog is only open to the users logged in, a Cookie file that can prove the identity of the crawler needs to be constructed at the same time. In addition, too frequent crawler request data will cause the server to terminate the request. Therefore, multiple Cookie files need to be configured for the crawler, and IP proxy technology is used to disperse the IP that initiates the data request to all parts of the country, so as to avoid the server "see through" the disguise of the crawler. After configuring the basic information of the crawler, the crawler carries the header file and Cookie file to the designated API interface point and requests the data from the server according to the specific parameters. The server then checks the header file and Cookie file. After successful verification, the data that meets the query conditions in the database is delivered to the crawler program, and the crawler program brings the data back to the local; after that, the lxml.etree module is used to organize the data into a standard HTML tree; finally, we can use pandas module to persist data into Excel file by using Xpath to match statements and extract formatted data.

3.2. Calculation of Public Perception Breadth. In this paper, the amount of information related to "intellectual property" appearing in microblog was counted mainly from four 
aspects of copyright, trademark, patent, and intellectual property, so as to analyze the public perception breadth and confirm the changing trend of public perception breadth based on the examples in microblog information.

3.2.1. Breadth of Public Perception of Copyright Topics. According to the release time of microblog and the monthly statistics of microblog volume, the trend of the change of public perception breadth of copyright is drawn as shown in Figure 1.

In 2010, the volume of microblog on copyright topics has been very low, indicating that copyright topics have not received public attention. In August 2011, the volume of microblog increased significantly. At the end of July 2010, China officially launched the "sword net action." At the end of 2010, the State Council launched a nationwide special action to crack down on intellectual property infringement and the production and sale of fake and shoddy goods. On November 17, 2012, the General Administration of Press and Publication of the People's Republic of China (GAPP) told the media that China's Copyright Law is being amended. One of the key points of amending the law is to strengthen legal punishment measures and strengthen law enforcement to protect intellectual property rights. This voice has aroused wide attention from all walks of life. At the same time, the volume of microblog on copyright topics has reached its peak in 8 years from 2010 to 2018 . However, China's “sword net action" ended in June 2014, and the volume of microblogs on copyright topics decreased accordingly, reaching the lowest level in eight years in July 2014. In January 2017, the public's perception of copyright topics increased significantly. According to the data from microblog, it can be found that, on January 20, 2017, the government released the first batch of copyright protection alert list of key works in 2017. This move of the government successfully aroused the public's attention on copyright topics again. Generally speaking, the public has a strong perception of copyright only when the government issues important documents, without great fluctuation in the remaining time.

\subsubsection{Public Perception Breadth of Trademark Topic.} Trademark is a kind of mark that uses words, patterns, or symbols to connect with specific goods or services [28]. The change trend of public perception breadth of trademarks is shown in Figure 2.

As can be seen from Figure 2, the public have been paying more attention to trademark rights. From July 2010 to October 2018, the volume of microblog about trademark basically remained stable. During the period from January to April in 2018, the amount of microblog increased sharply. On the World Intellectual Property Day in April 2018, the Supreme People's Court held a public session and ruled that the trademark application of France DIOR Company was rejected for reexamination of the administrative dispute. This event was a sensation at that time, and the public's discussion on this matter was one after another.
3.2.3. Public Perception Breadth of Patent Topics. Patent is an important part of intellectual property and a very important intangible asset [29]. The change trend of the public perception breadth of patent topics is shown in Figure 3.

It can be seen that, from January 2010 to June 2011, the microblog volume of patent topics has been low. During the period from July to October 2011, the volume of patent related microblog has increased, and there is no obvious downward trend since then. According to microblog information, Intellectual Ventures, a patent company, filed a patent infringement lawsuit against Nikon on digital camera technology in the middle of 2011, which greatly aroused the public's attention to the patent right. From January to April 2018, the press circles vigorously publicized the government documents and policies such as the Catalogue of Key Supporting Industries of Intellectual Property Rights (2018 Edition) and the Opinions on Several Issues of Strengthening the Reform and Innovation in the Field of Intellectual Property issued by the China State Council, so as to enhance the public's awareness of intellectual property rights and raise public attention.

3.2.4. Public Perception Breadth of Intellectual Property Topics. Intellectual property here refers to the information related to "intellectual property," but cannot be classified into the above three categories. The change trend of public perception breadth of intellectual property topics is shown in Figure 4.

As can be seen from Figure 4, the public perception breadth of intellectual property topics during the period from July 2011 to July 2018 fluctuates little, but it suddenly rises substantially in October 2018. In October, 2018, the 7th China International Copyright Expo opened in Jiangsu Province, and the "China Copyright Gold Award" was announced. In this activity, the more concerned film and television works, such as the Operation Red Sea, were awarded the prize, which aroused public resonance, thus successfully expanding the public perception breadth of intellectual property topics.

Generally speaking, the contents that can arouse public attention mainly focus on personal benefits, enterprise benefits, and personal interest.

3.3. Calculation of Public Perception Depth. According to the release time of microblog, the total numbers of likes, forwards, and comments on the four topics of copyright, trademark, patent, and intellectual property are counted monthly.

3.3.1. Public Perception Depth of Copyright Topic. The change trend of public perception depth of copyright topics is shown in Figure 5.

On the whole, the degree of public participation in the dissemination of public opinion on copyright topics mainly belongs to the surface perception, while the deep perception is less; that is, the public mostly express their approval of copyright topics through "like" behavior. Surface perception 


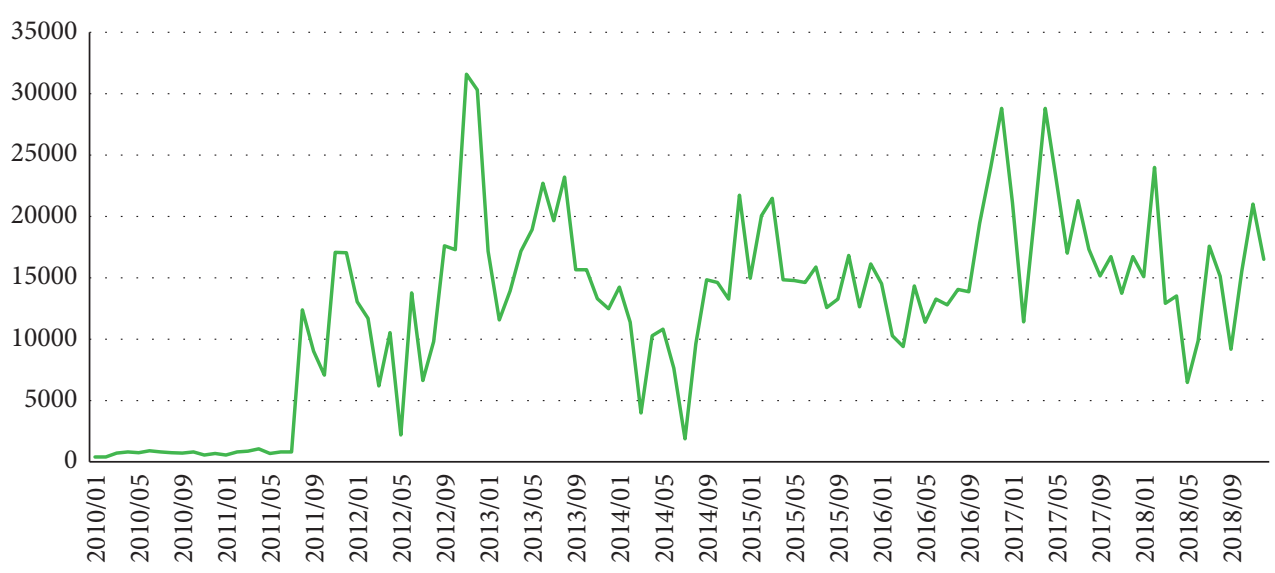

FIgURE 1: Change trend chart of public perception breadth of copyright.

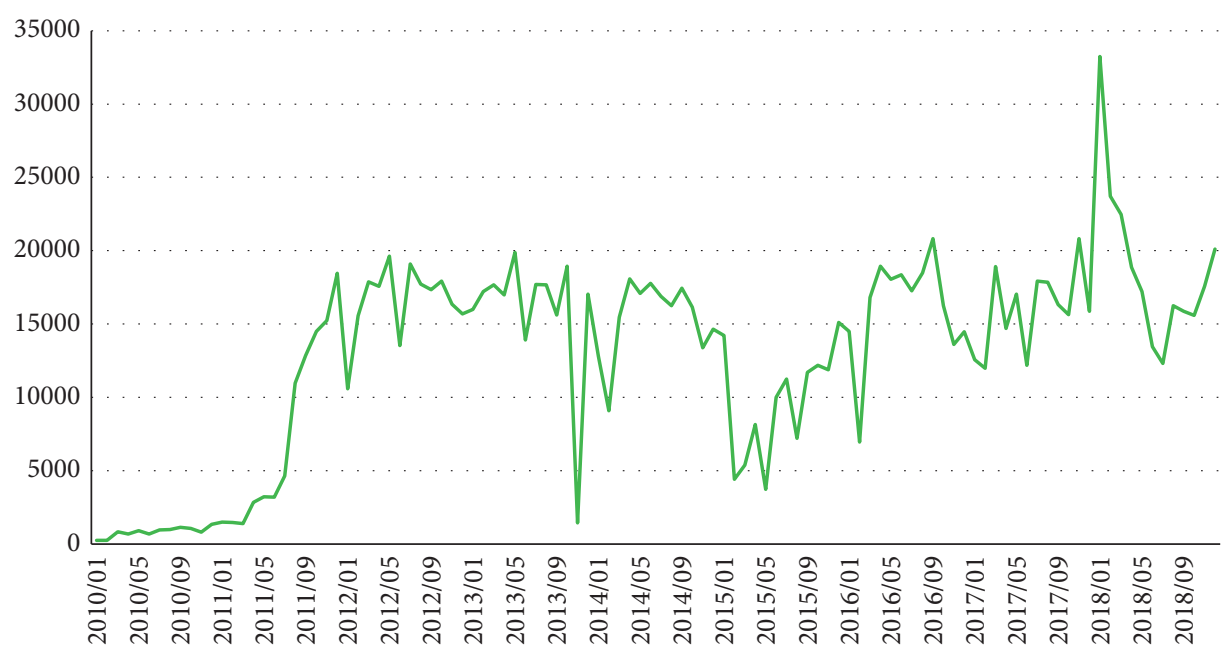

Figure 2: Change trend diagram of public perception breadth of trademarks.

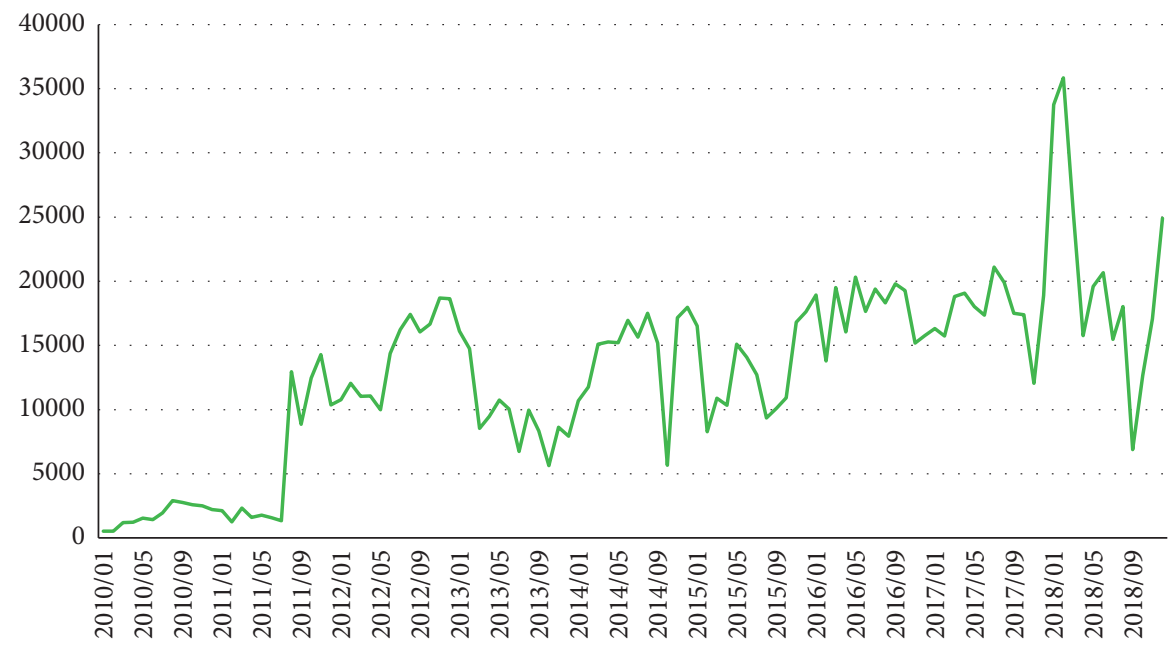

FIGURE 3: Change trend diagram of public perception breadth of patent topics.

was the most obvious from January 2015 to September 2018. According to the survey of microblog data, the topic most praised in 2016 was "top 10 patent agents in China in 2016." From May to September 2018, the public gave the largest number of likes to the topic of European patent application ranking, reaching the highest level in eight years. In 2013 and October 2018, shallow perception dominated. According to microblog data, the most commented cases in 2013 were 


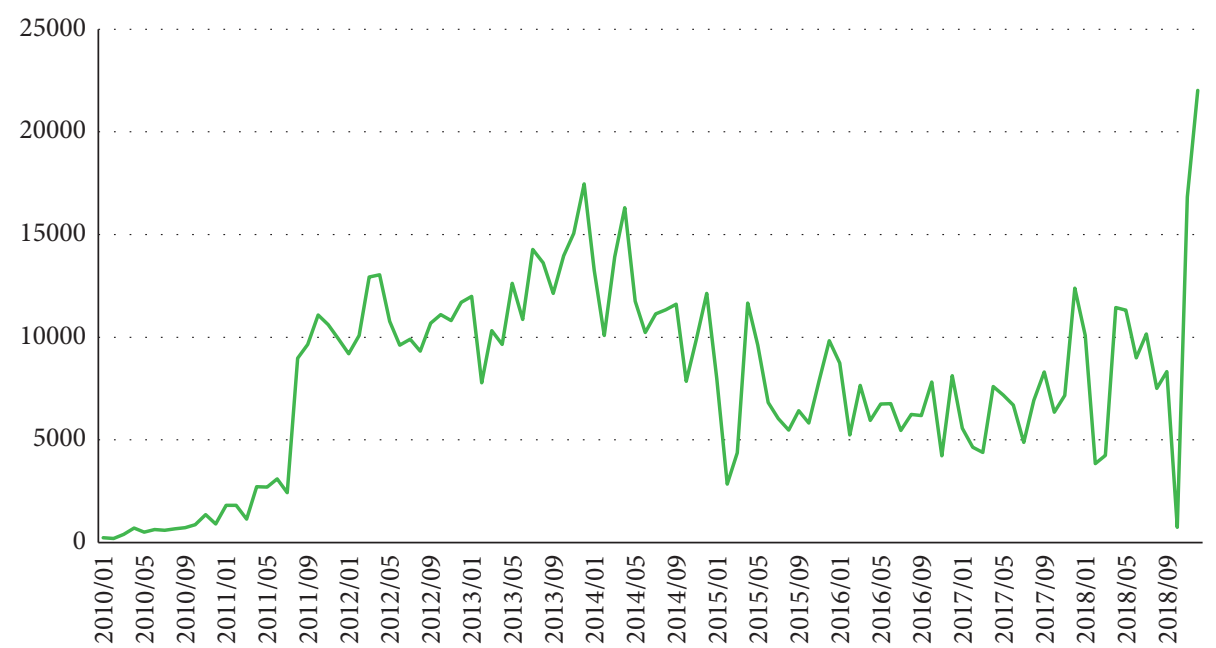

FIgURE 4: Change trend of public perception breadth of intellectual property topics.

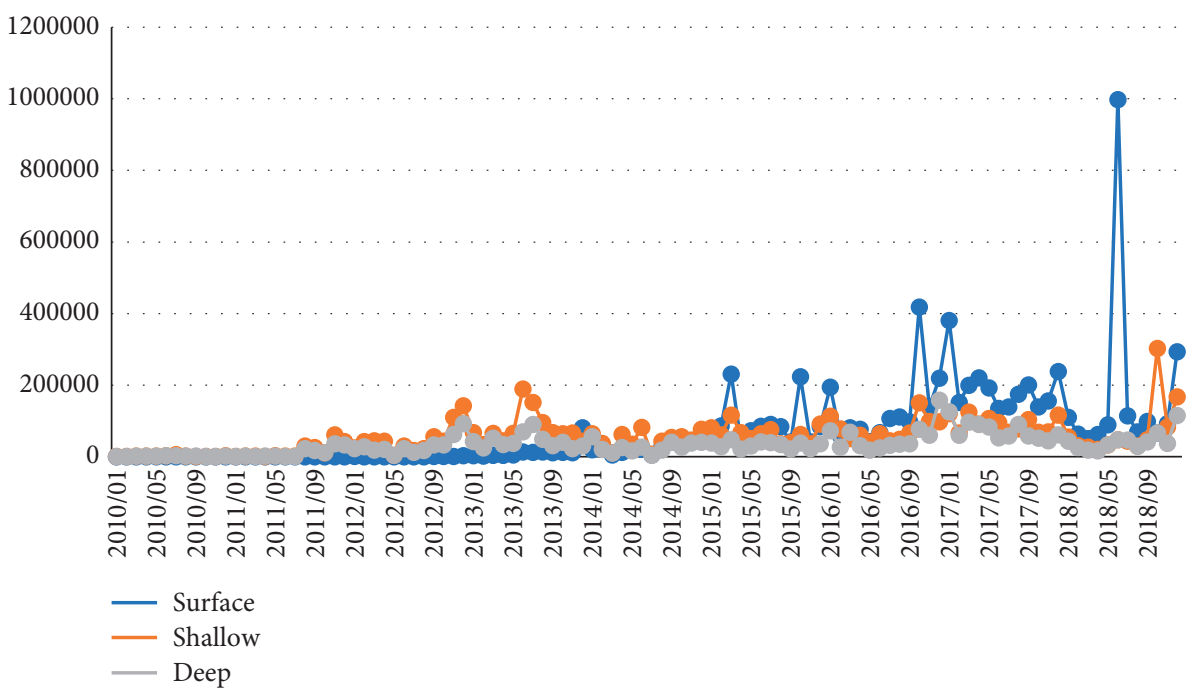

FIGURE 5: Change trend of public perception depth of copyright topics.

“top 10 cases of Patent Reexamination Board in 2013", and in October 2018, the most forwarded case was "speech delivered by Xiang Songzuo at CBD multinational forum.”

3.3.2. Public Perception Depth of Trademark Topics. The change trend of public perception depth of trademark topic is shown in Figure 6.

In general, except for the sudden increase of surface perception in January 2018, the change trend of public perception in the other three layers (surface layer, shallow layer, and deep layer) is basically consistent. Microblog data show that, in January 2018, "trademark rights of historical figures" caused widespread public attention to trademark rights and received a lot of likes, so the surface perception increased significantly at this time.

3.3.3. Public Perception Depth of Intellectual Property Right Topics. The change trend of public perception depth of intellectual property right topics is shown in Figure 7.
There are five peaks in the public perception depth of intellectual property rights: in January 2012, there was a large amount of deep perception, and the microblog topic "the relationship between China's economy and intellectual property rights, which indicates that China needs to strengthen the protection of intellectual property rights to stabilize the economy" received the most comments; at the end of 2012, there was a large amount of shallow perception, and a microblog topic about "Samsung and iPhone build LTE patent library and open up a new battlefield of intellectual property rights" was forwarded the most. From April to July 2013, the amount of shallow perception was significantly higher than that of the surface and deep perception. The event of "China's first large load vacuum manipulator with independent intellectual property rights was successfully developed in Shenyang SIASUN Robot and Automation Co., Ltd." was noticed and forwarded by the majority of users; in the period from January to April 2014 with the largest fluctuation, the event of "Shenzhen Institute of Special Equipment Inspection and Test won the national 


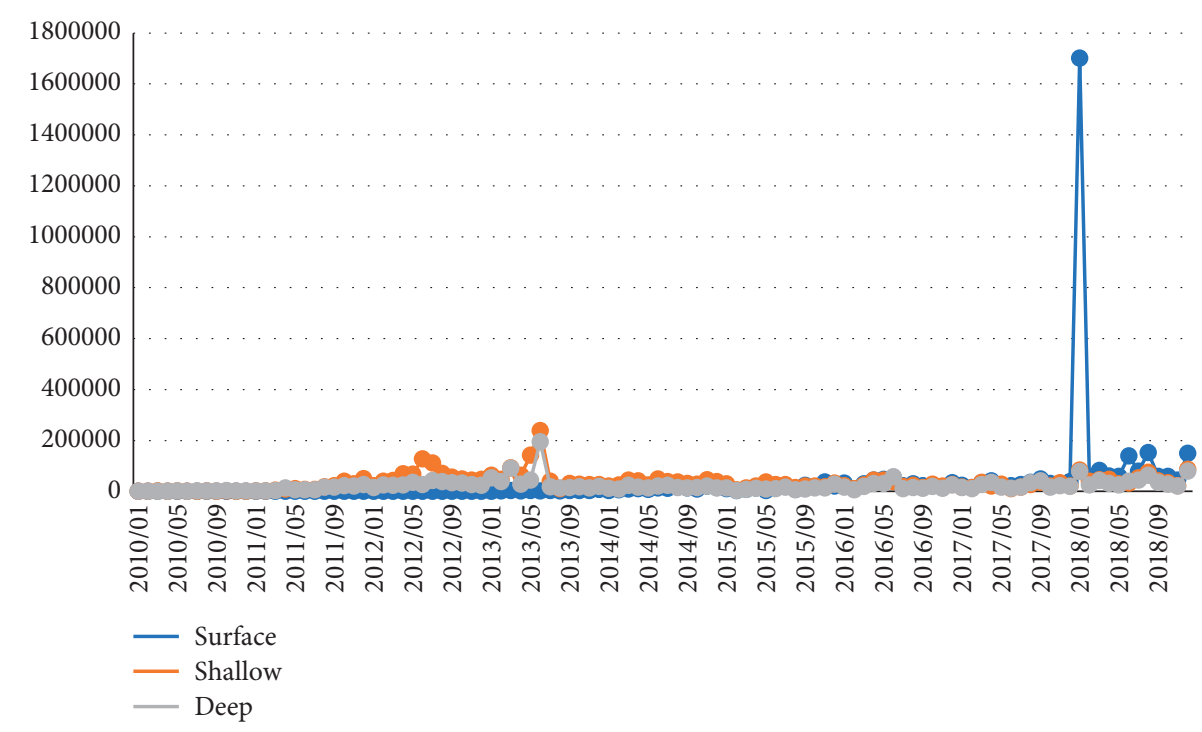

Figure 6: Change trend of public perception depth of trademark topics.

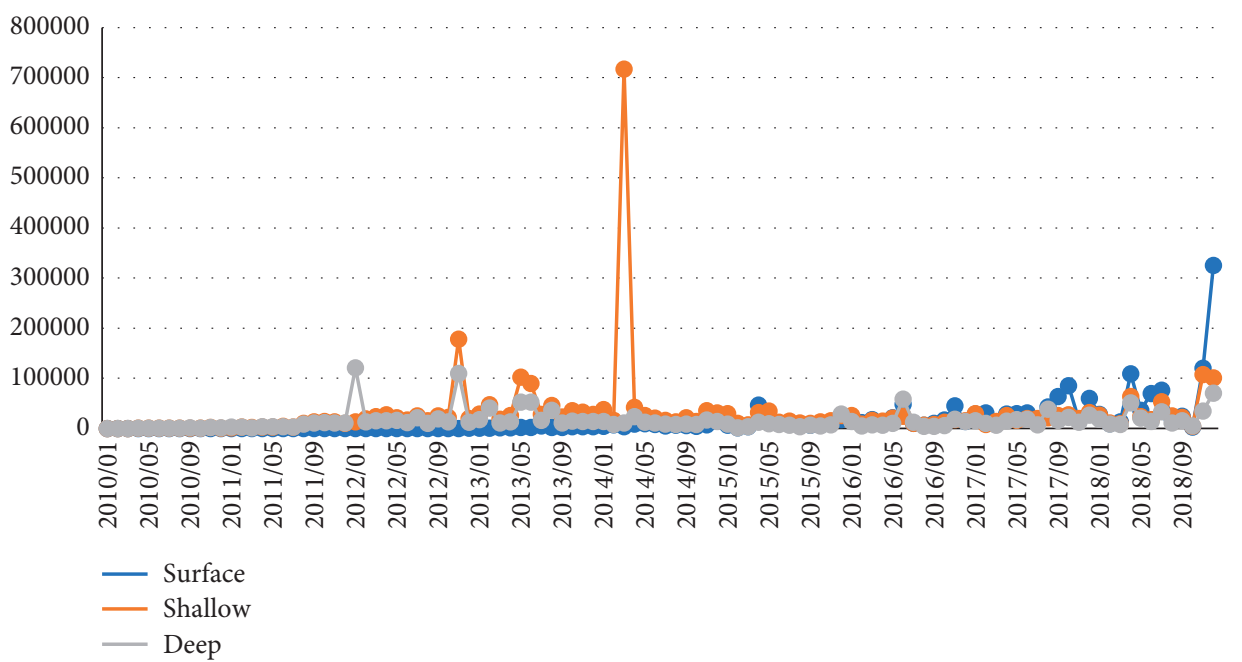

FIGURE 7: Change trend of public perception depth of intellectual property right topics.

invention patent authorization" caused a sensation, which pushed the shallow perception of intellectual property to the peak; finally, in the period from October to December in 2018, there was a large fluctuation; the surface perception was much higher than the shallow and deep perception and the event "Wenzhou high-tech zone passed the assessment and acceptance of national intellectual property pilot park" received the largest number of likes.

3.3.4. Public Perception Depth of Patent Topic. The change trend of public perception depth of patent topic is shown in Figure 8.

It can be seen that, from July 2011 to April 2017, the shallow perception of patent is basically ahead of the other two levels of perception. In January 2016, the shallow perception reached the peak. In this period, the most forwarded content by users is related to music, works, and other related microblogs that have been removed due to copyright issues. From May 2017 to September 2018, it shifted to surface perception, especially reaching the peak of surface perception in September 2017. The problem that the game design of DOTA2 could not be restored 1:1 caused public resonance due to copyright problems.

Generally, the public participation in the dissemination of public opinion on intellectual property topics is mainly surface and shallow perception, with less deep perception; that is, microblog users mainly interact and express their emotions by forward and like behaviors related to intellectual property content, rather than directly expressing their opinions. After the government issued the intellectual property-related policies, the public mostly expressed their approval for the policies through the behavior of "like." In addition, the public would give "likes" to the intellectual property-related topics such as personal favorite books and movies. Generally, microblog is more likely to lead the people to forward a major event that can affect the interests of the company. However, the shallow perception of policy 


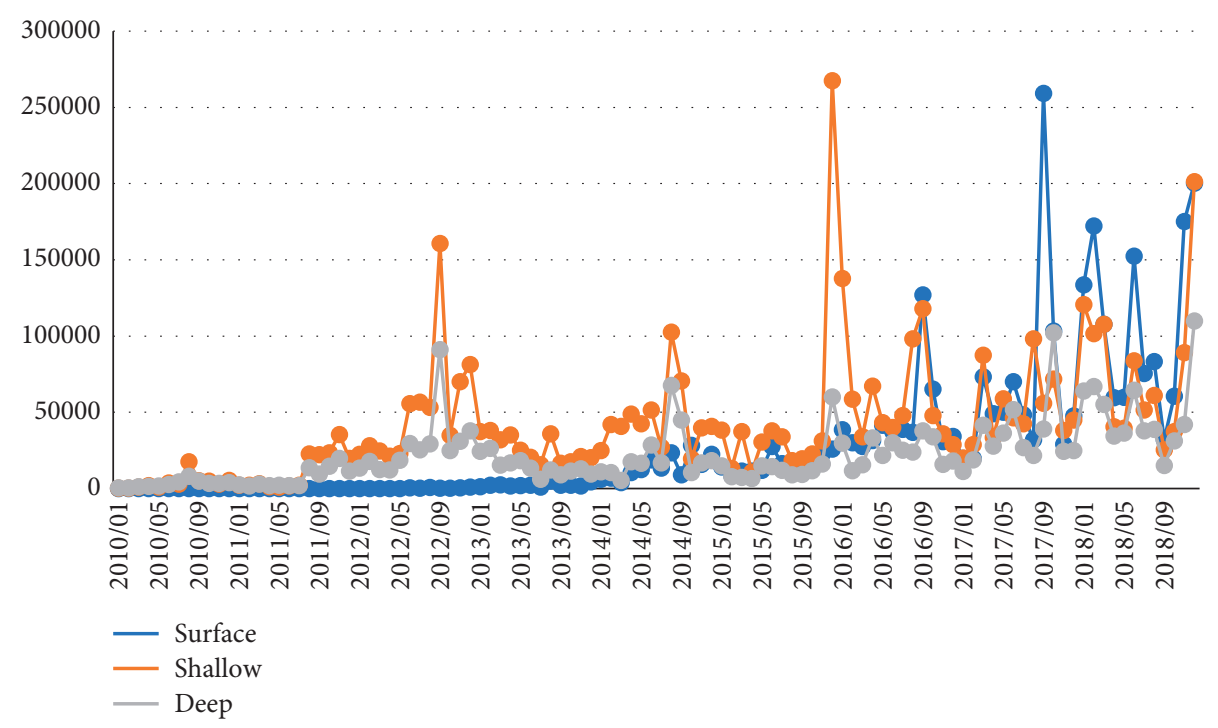

Figure 8: Change trend of public perception depth of patent topic.

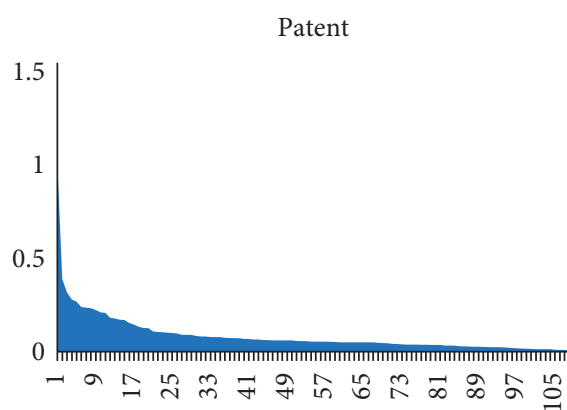

(a)

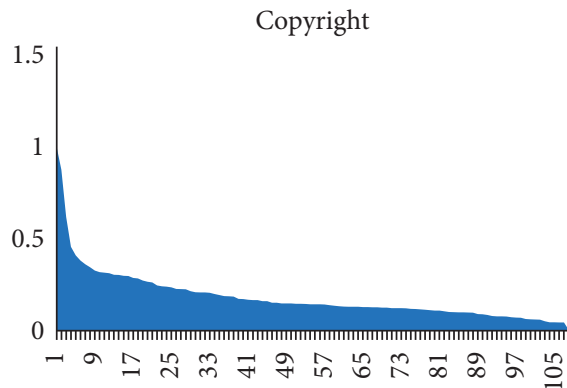

(c)

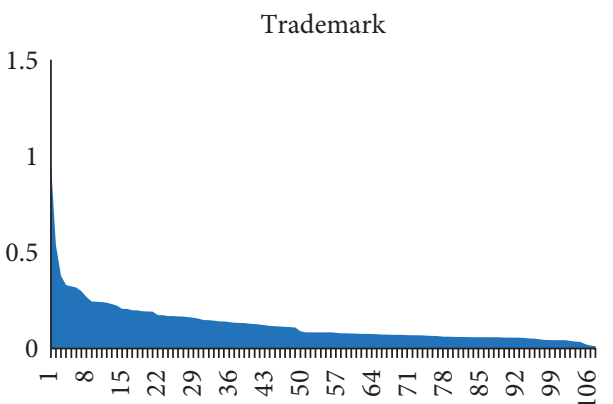

(b)

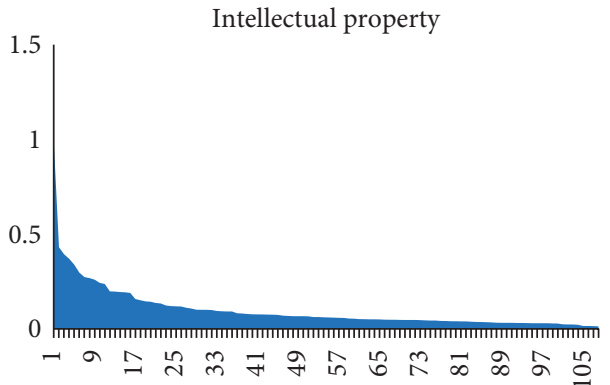

(d)

FIGURE 9: Distribution of comprehensive value of public perception of patent, trademark, copyright, and intellectual property.

topics related to personal state is very little, and the microblog content that can cause deep perception is usually related to forwarding lottery, star endorsement, and so on.

\subsection{Comprehensive Value Calculation of Public Perception.} First, based on the data collected in this paper, the combination weight of comment is $W_{1}=0.2$, the combination weight of forward is $W_{2}=0.45$, and the combination weight of like is $W_{3}=0.35$. Then, according to (2), the comprehensive value of public perception of copyright, trademark, patent, and intellectual property in 2010-2018 is calculated by month, and the value is standardized to be between 0 and 1. The results are shown in Figure 9.

It can be seen from Figure 9 that the overall change trends of the distribution of the comprehensive value of public perception of patent, trademark, copyright, and intellectual property are basically the same. The long tail degree of "trademark" and "copyright" is lightly lower than that of "intellectual property" and "patent," and the long tail data of the comprehensive value of public perception of intellectual property and patent is close to 0 , indicating that 
microblog users pay less and less attention to them, and the public perception is negligible, and even the amount of likes, forwards, and comments is almost zero. The long tail comprehensive value of public perception of trademark and copyright is about 0.1 , and microblog users still give "like, forward, or comment" on microblogs with such topics, which indicates that these two aspects have been highly concerned by microblog users.

\section{Conclusions and Implications}

Based on microblog data, this paper takes patent, trademark, copyright, and intellectual property as the research objects and analyzes the perception of online public opinion on intellectual property in China from three aspects: the breadth, depth, and comprehensive value of public perception. Through the analysis of public perception of intellectual property topics, this paper summarizes the basic rules and characteristics of intellectual property topics being concerned by the public. This will help managers to have a deep understanding of the practical problems and public opinions existing in their own country or region's intellectual property policies and provide scientific suggestions for the adjustment of intellectual property system, policies, and related working methods. Therefore, this paper puts forward the following countermeasures and suggestions:

(1) As an important factor to strengthen the awareness of intellectual property protection, the government should vigorously publicize the policy of intellectual property protection in combination with the current mainstream media to enhance the awareness of individual intellectual property protection. For example, we should publicize the content and activities of intellectual property policies with WeChat official account and microblog platform and pay attention to the public perception of intellectual property topics through the new media platform.

(2) Construct the network guidance mechanism of intellectual property. That is to say, scientific methods should be adopted under the guidance of the government to pay close attention to the public's demands for intellectual property topics and the tendency of public opinion, and reasonable and effective methods should be adopted to guide the public to actively respond to intellectual property policies, improve the social influence of mainstream topics, and minimize the harm of bad public opinion on mainstream consciousness.

(3) The coordination and cooperation among the government, new media, and society can maximize the overall effect mechanism and improve the effectiveness of intellectual property policy implementation. Specifically, on the one hand, media is the most convenient and effective channel for the dissemination of intellectual property policy. Therefore, the government should actively cooperate with the media to expand the intellectual property policy and strengthen the means of collecting valuable information by using the media communication advantages, so as to grasp the public response to the intellectual property policy in time and absorb valuable suggestions to further improve the intellectual property policy. On the other hand, the government should always pay attention to the speech of "signs" related to intellectual property policy and deal with it in time to prevent things from developing out of control and leading to public opinion crisis.

\section{Data Availability}

The data used to support the findings of this study are included within the article.

\section{Conflicts of Interest}

The author declares that there are no conflicts of interest regarding the publication of this paper.

\section{References}

[1] Y. Liu, An Introduction to the Study of Network Public Opinion, Tianjin People's Publishing House, Tianjin, China, 2007.

[2] J. P. Zhu, B. C. Xie, and X. Y. Luo, "China real estate network public opinion analysis," Journal of Applied Statistics and Management, vol. 35, no. 4, pp. 722-741, 2016.

[3] D. H. Folz, Survey Research for Public Administration, Sage Publications, Thousand Oaks, CA, USA, 1996.

[4] Y. A. Zhang and C. G. Li, "Construction of echo model of regional enterprises responding to science and technology policy innovation," Science of Science and Management of ST Monthly, vol. 9, pp. 86-96, 2013.

[5] T. M. Harrison, "Building government's capacity for big data analysis," in Proceedings of the 15th Annual International Conference on Digital Government Research, pp. 306-308, ACM, New York, NY, USA, June 2014.

[6] B. Johan, M. Huina, and Z. Xiaojun, "Twitter mood predicts the stock market," Journal of Computational Science, vol. 2, no. 1, pp. 1-8, 2011.

[7] P. K. Andrei and O. S. Svetlana, "Public microblogging on climate change: one year of Twitter worldwide," Global Environmental Change, vol. 26, pp. 171-182, 2014.

[8] A. J. Lazard, G. B. Wilcox, H. M. Tuttle, E. M. Glowacki, and J. Pikowski, "Public reactions to e-cigarette regulations on Twitter: a text mining analysis," Tobacco Control, vol. 26, no. e2, pp. e112-e116, 2017.

[9] X. Li, Q. Xie, and L. Huang, "Identifying the development trends of emerging technologies using patent analysis and web news data mining: the case of perovskite solar cell technology," IEEE Transactions on Engineering Management, vol. 16, 2020.

[10] E. Mohammadi, K. B. Gregory, and M. Thelwall, "Which health and biomedical topics generate the most Facebook interest and the strongest citation relationships?" Information Processing \& Management, vol. 57, no. 3, Article ID 102230, 2020.

[11] Z. L. Yang, W. Zhang, F. Yuan, and N. Islam, "Measuring topic network centrality for identifying technology and technological development in online communities," 
Technological Forecasting \& Social Change, vol. 67, Article ID 120673, 2021.

[12] M. Vanhala, C. Lu, J. Peltonen, S. Sundqvist, J. Nummenmaa, and K. Järvelin, "The usage of large data sets in online consumer behaviour: a bibliometric and computational textmining-driven analysis of previous research," Journal of Business Research, vol. 106, pp. 46-59, 2020.

[13] Z. L. Yang, N. Islam, Y. Shi, K. Venkatachalam, and L. Huang, "The evolution of interindustry technology linkage topics and its analysis framework in 3D printing technology," IEEE Transactions on Engineering Management, vol. 30, 2021.

[14] S. S. Jia, "Motivation and satisfaction of Chinese and US tourists in restaurants: a cross-cultural text mining of online reviews," Tourism Management, vol. 78, Article ID 104071, 2020.

[15] H. Chun, B. H. Leem, and H. Suh, "Using text analytics to measure an effect of topics and sentiments on social-media engagement: focusing on Facebook fan page of Toyota," International Journal of Engineering Business Management, vol. 13, 2021.

[16] W. Wang, "Data analysis of intellectual property policy system based on Internet of Things," Enterprise Information Systems, vol. 14, no. 9-10, pp. 1475-1493, 2020.

[17] K. Ariel, "Intellectual property, antitrust, and the rule of law: between private power and state power," Theoretical Inquiries in Law, vol. 17, no. 2, 2016.

[18] Y. G. Xie and Y. Xu, "The history, present situation and development trend of microblogging," Journal of Communication University of China Science and Technology, vol. 4, pp. 75-80, 2011.

[19] Y. G. Xie and T. Rong, "Microblog public opinion generation and evolution mechanism and public opinion guidance strategy," Journal of Communication University of China Science and Technology, vol. 5, pp. 70-74, 2011.

[20] H. M. Zhu and Q. Li, "Research on the model of weibo network public sentiment communication oriented to topic derivatives," Data Analysis and Knowledge Discovery, vol. 5, pp. 60-64, 2012.

[21] J. D. Creutin, M. Borga, and C. Lutoff, "Catchment dynamics and social response during flash floods: the potential of radar rainfall monitoring for warning procedures," Meteorological Applications, vol. 16, no. 1, pp. 115-125, 2010.

[22] J. B. Houston, J. Hawthorne, M. F. Perreault et al., "Social media and disasters: a functional framework for social media use in disaster planning, response, and research," Disasters, vol. 39, no. 1, pp. 1-22, 2014.

[23] S. M. Fast, L. Kim, E. L. Cohn, S. R. Mekaru, J. S. Brownstein, and N. Markuzon, "Predicting social response to infectious disease outbreaks from internet-based news streams," Annals of Operations Research, vol. 263, no. 1, pp. 551-564, 2018.

[24] L. Liu, K. J. Zhang, and J. Su, "A comparative study on rainstorm response behavior during flood season in Beijing in 2012 and 2013," Journal of Natural Disasters, vol. 25, no. 1, pp. 26-34, 2016.

[25] Y. X. He, J. B. Liu, N. Liu, M. Peng, Q. Chen, and J. He, "Microblog topic trend prediction based on improved population model," Journal on Communications, vol. 36, no. 4, pp. 5-12, 2015.

[26] J. Y. Ma, Y. S. Fu, and Z. L. Zhang, "Preschool education fee becomes a restrictive factor for parents to give birth to a second child -- a case study of "two-child policy" liberalization based on microblog data," China Management Informationization, vol. 19, no. 13, pp. 166-170, 2016.
[27] Z. M. Tan, "Design and comprehensive measurement of regional financial risk early warning system," Soft Science, vol. 24, no. 3, pp. 69-74, 2010.

[28] C. T. Liu, "Differentiation and analysis of trademark and trademark right," Intellectual Property, vol. 1, pp. 10-14, 1998.

[29] X. L. Wan and X. Z. Zhu, "Evaluation index system of patent value and fuzzy comprehensive evaluation," Science Research Management, vol. 2, pp. 185-191, 2008. 